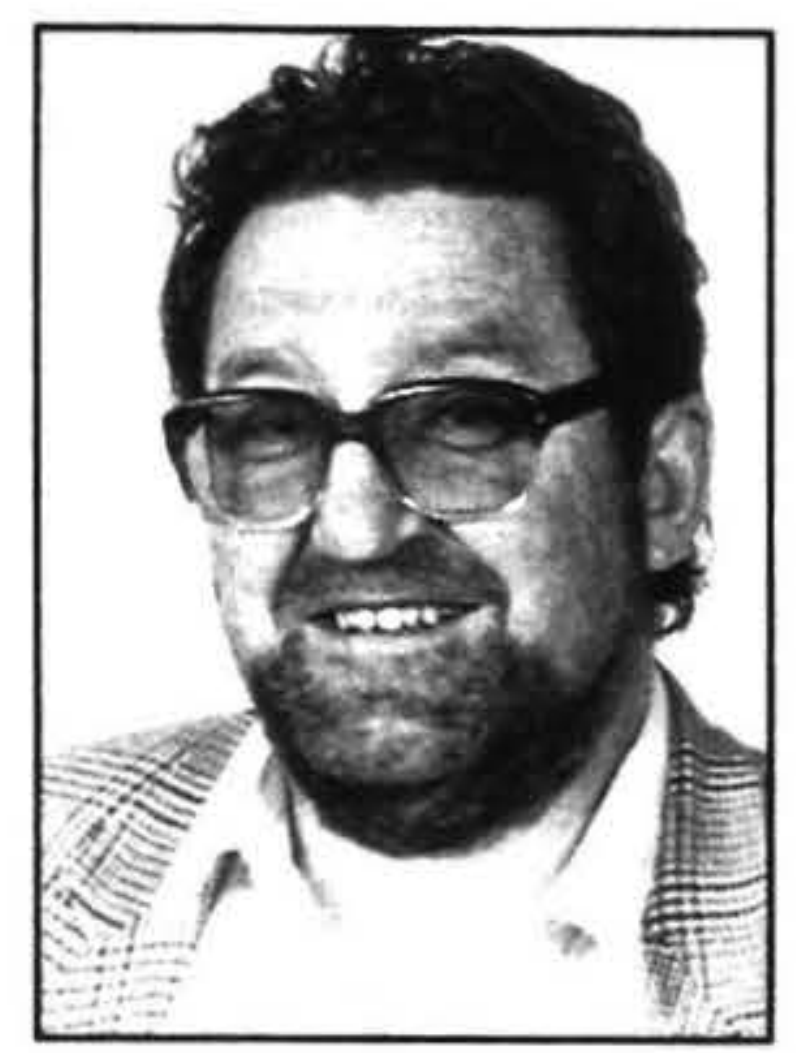

\title{
SOME MACROECONOMICS OF THE EMPLOYMENT CONTRACTS ACT
}

\author{
Brian Easton \\ Economic And Social Trust On New Zealand
}

\begin{abstract}
Earlier this year Wolfgang Kasper produced a book "Free to Work: The Liberalization of new Zealand's Labour Markets" (Centre for Independent Studies). By reviewing this book, the paper is able to shed some understanding of the effectiveness or otherwise of the Employments Contract Act. On the basis of the empirical evidence it is very difficult to reach, in a systematic way, Kasper's conclusions about the beneficial effects of the Employment Contract Act. In particular the poor productivity growth rules out the likelihood that the ECA was a major contributor to the macroeconomic expansion of the mid 1990s. The Act would, however, seem to have contributed to the poor real wage growth, and the failure of many workers to obtain a share in any increase in prosperity of the 1990s.
\end{abstract}

Were he alive, John Stuart Mill would be greatly puzzled by the naivety of the methodology used in the economic debate in New Zealand. Suppose the advocate has a theory which says if event A occurs, then event B will occur, and then something like event A does occur, and some time after something like event B occurs. This is then treated as proof of the validity of the theory. There is no attempt to consider whether A caused B, for association is sufficient. Moreover, suppose the theory also predicts that if $\mathrm{A}$ occurs then event $\mathrm{C}$ will occur, and in fact not-C actually occurs after A occurs. That not- $\mathrm{C}$ may be ignored, since the evidence of $\mathrm{B}$ is sufficient to "prove" the theory's truth, and so there must be some other mitigating factor which invalidates the theory's account of the causal impact from A to C.

Thus are theories are defended, and the policies derived from them are justified. It is extremely difficult to challenge any theory in such circumstances, because there is always some event B, predicted by the theory, which will occur, while numerous other not-C events which occur cannot be used to discredit the theory. Moreover numerous theories will be confirmed by this weak methodology, which has no criteria for deciding between them. It becomes a matter of the belief of each theory's supporter. Where there are more than one supporter, their mutual belief reinforces one another's confidence.

John Stuart Mill would despair at being unable to make any progress towards resolving the macroeconomic questions which confront New Zealand. He would want to use a much tougher methodology. At the very least he would want to compare various theories and see which gave a consistent account of more of the events which occurred.

In order to avoid some of these difficulties, this paper uses those in Wolfgang Kasper's Free to Work, ${ }^{1}$ which - as we shall see - selectively reviews the available data and uncritically concludes that the Employment Contracts Act has benefited the economy. The merit of using his criteria - selecting his concepts, definitions, and periods - as the basis for a critique, is that it stacks the odds in favour of his support for the Employment Contracts Act (ECA). Yet we shall see that the case he makes of the macroeconomic benefits of the ECA is not compelling.

\section{GDP growth}

Kasper claims that the ECA stimulated economic growth, but is rather vague about how that occurred. Figure 1 repeats the first graph of Kasper's Figure 2, but includes more recent (and revised) data, and projects the GDP figures through to March 1999, using the September 1996 NZIER consensus forecasts, which average the predictions of 14 forecasters. ${ }^{2}$ In addition a 'trend' growth rate of 3 percent p.a. is shown.

The story it shows is clear enough, if unrecognized by Kasper. The New Zealand economy contracted and stagnated from 1990 (in fact from 1989) through to end 1992. From late 1992 the economy began a rapid (and widely hailed) expansion. ${ }^{3}$ However this was not long enough to catch up to the 3 percent trend line. After 10 quarters the growth petered out, and was expanding at 2.8 percent in the year through to March 1996 and, according to the forecasters' average, by 1.8 percent in the (current) year to March 1997. Further out the forecasters expected growth to hover around 3 percent a year. ${ }^{4}$ This contrasts with Kasper's claim that "the projection is for the economy is to keep growing for the remainder of the decade at a trend growth rate of around 4 percent." (p.16) 
Figure 1. Real GDP growth in New Zealand, 1990 to 1996 with forecasts to 1999

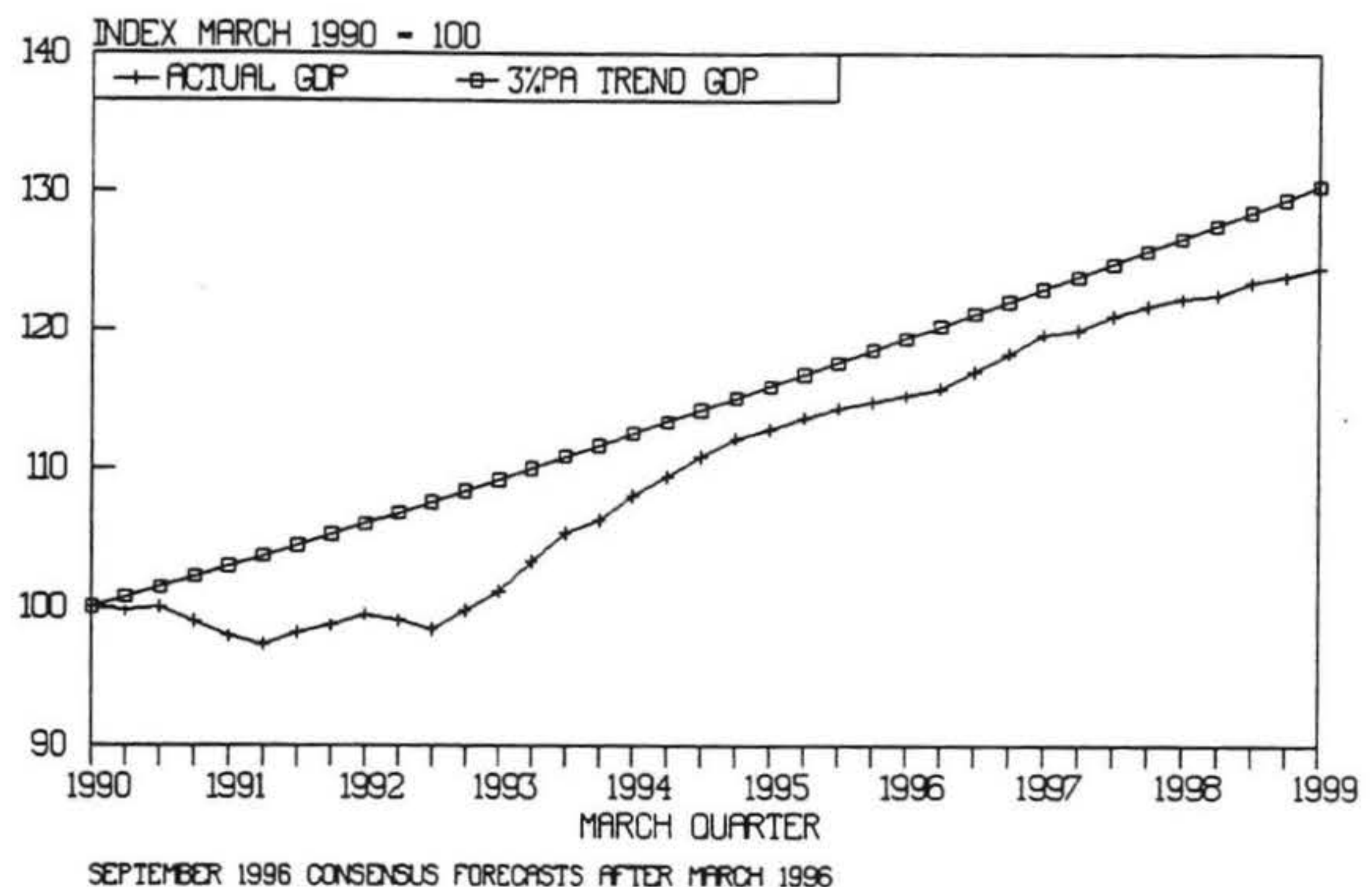

\section{Real wages}

Kasper used a different presentation for his second graph of real wages changes. As Figure 2 shows, his presentation obscures how minuscule real (income) wage growth over the period has been - about 2 percent over seven years, with little prospect of further gains. ${ }^{5}$ Probably part of the gains due to labour force composition effects. Hence the increase in real wages as the economy contracted and so lower paid workers were laid off, and the fall during the early part of the upswing. Kasper's own estimate is a 0.4 percent average growth of real wages. In summary, within the margin of error, and allowing for composition effects, real wages have hardly increased over the period.

\section{Labour productivity growth}

As the third of Kasper's graphs shows, employment numbers rose sharply from mid 1993, as one might expect in a cyclical upswing. Initially firms expanded output by increasing the intensity of labour usage within the firm, and as under-utilized labour became exhausted they turned to an extensive expansion of hiring more workers.

However Kasper does not consider the implications of high employment growth with modest output growth. As Figure 3 shows, the productivity growth record for the New Zealand economy has been poor. In the seven years from 1990 there was a total gain of around 5 percent, and the forecasters do not expect any major increases in the immediate

Figure 2. Real wages index for New Zealand, 1990 through 1996

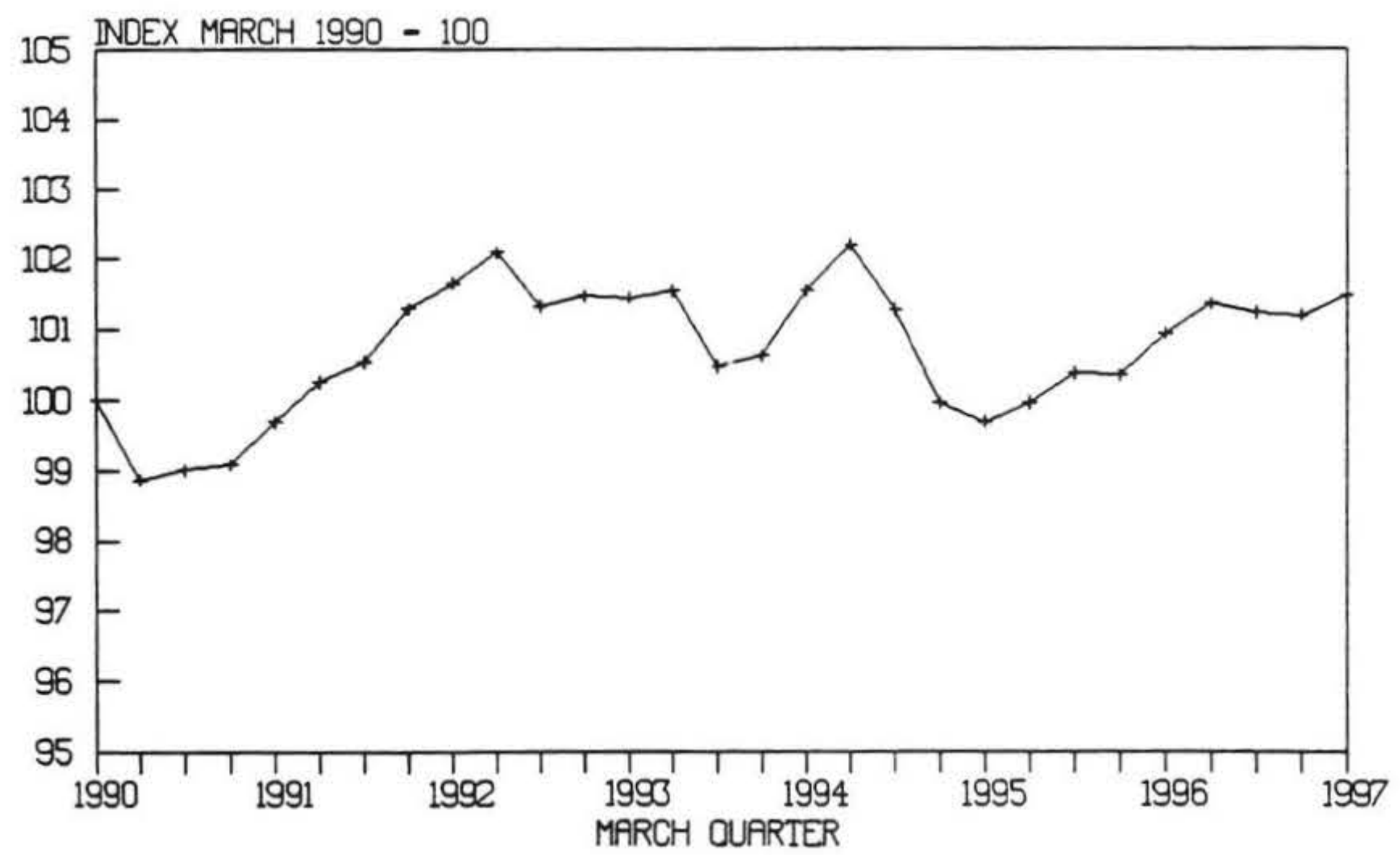




\section{Figure 3. Productivity (average output per worker) in New Zealand, 1990 through 1996}

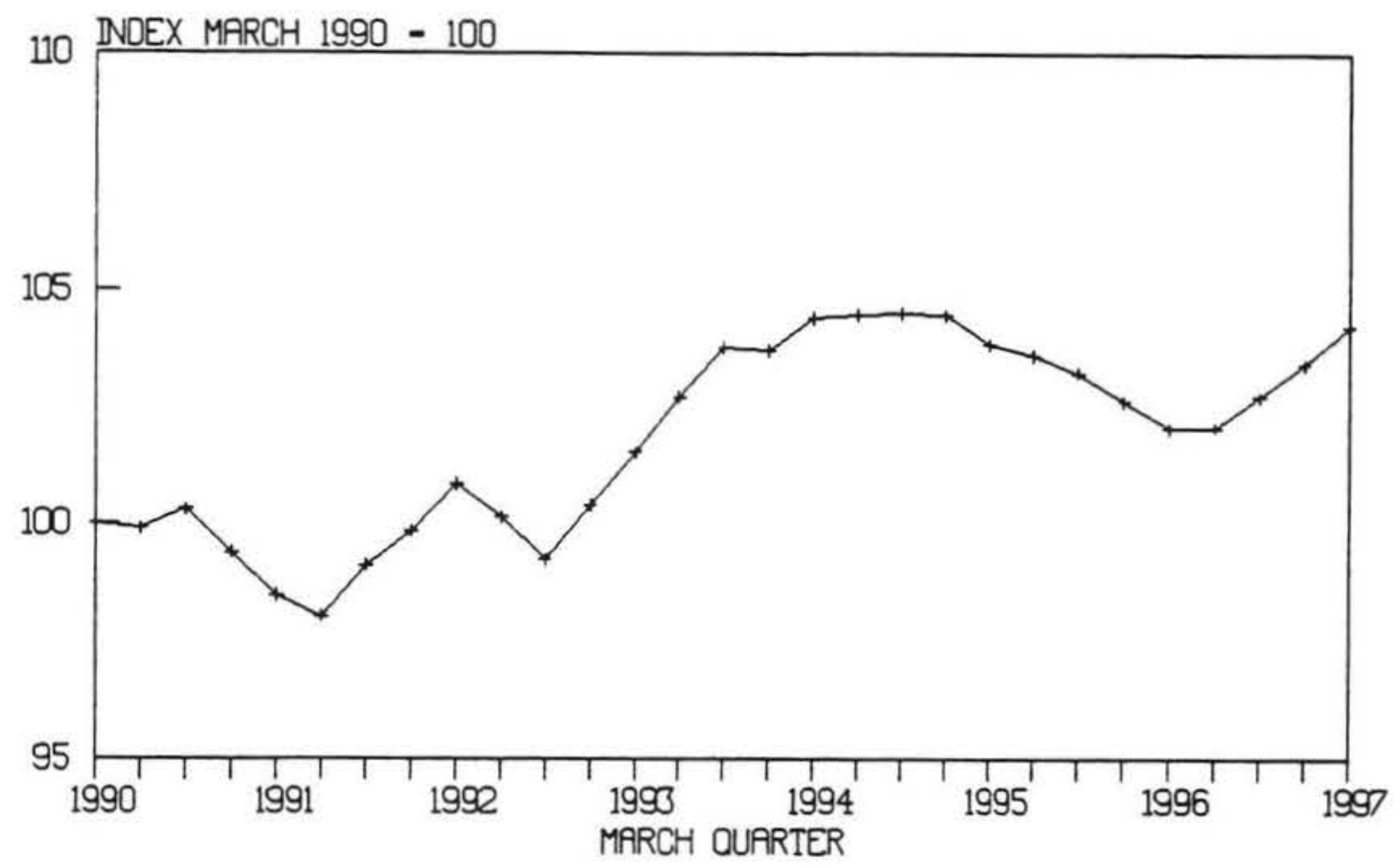

future. It is also evident that the big gains came during the period of the early upswing, when firms used their existing labour force more intensively.

One might contrast this with the story which Kasper tells about the Australian economy. It has not been possible to check his statistics, but an eyeball of his data (p. 50-1) shows almost the same output growth over the period from 1990 to 1995, except the Australian upswing was later and faster than the New Zealand one. However Australia experienced much less employment growth, by about 1 percent a year. Thus Australian productivity growth has outperformed New Zealand productivity growth - by about 1 percent a year. Given this evidence it is difficult to "conclude that the
Employment Contracts Act has substantially enhanced the productivity of labour ..." (p.51) ${ }^{6}$

\section{The productivity puzzle}

The productivity puzzle deserves further investigation. Detailed work by Bryan Philpott has provided a productivity series for the New Zealand economy back to $1977 / 8 .^{7}$ Three sectors -importables, exportables, and non-tradeables - are graphed in Figure 4. It is extremely hard to discern any significant change in the trend of any of the three series, once allowance is made for cyclical effects and measurement problems. ${ }^{8}$ Despite all the changes in the last decade, there is no perceptible impact of the reforms on the long run

Figure 4. The productivity puzzle. Average labour productivity in New Zealand, 1978 through 1995

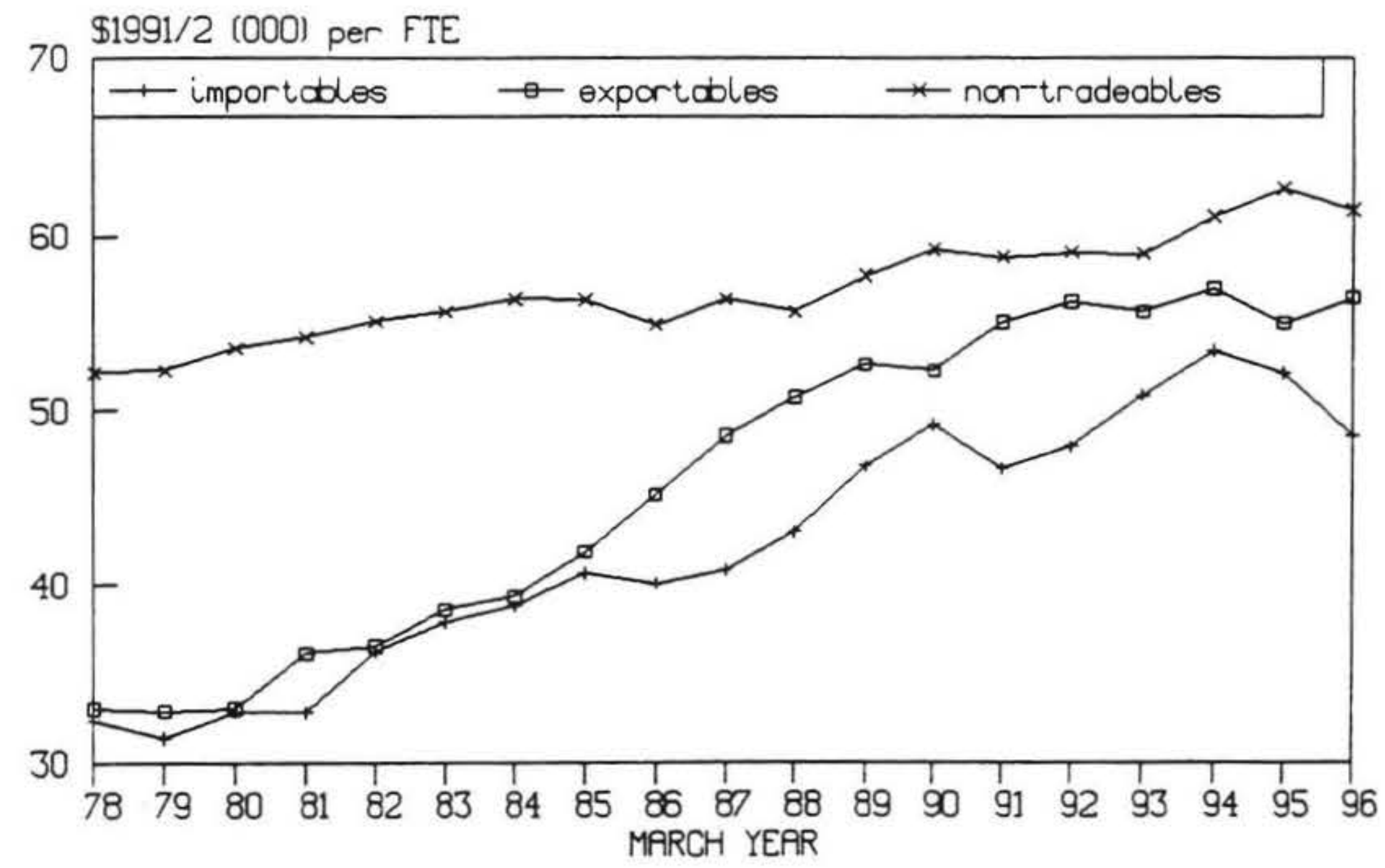


Table 1. Annual increases in average labour productivity growth (\% p.a.)

Sector

Importables

Exportables

Non-Tradeables

ALL SECTORS (GDP)

Unrestructured Sectors

Restructured Sectors
$1977 / 8-1985 / 6$

2.7

4.0

0.6

1.6

1.3

3.7
$1985 / 6-1990 / 1$

3.1

4.0

1.4

2.2

1.4

8.9
$1990 / 1-1995 / 6$

0.8

2.6

0.9

0.8

0.2

5.1 trend of overall productivity. This is true for the post-ECA era, and is true for the post 1984 era as well.

One could even argue there has been a reduction in productivity growth in the five years after March 1991 compared to the five years which preceded it. Table 1 makes it hard to argue that there has been a definite increase in the productivity growth rate after the ECA was introduced, in contrast to the previous quinquennium. Indeed, as a rule the sectoral productivity growth rates in the first part of the 1990s appear to be lower than the rates before the restructuring began.

Even the exceptions can be explained. Figure 5 summarizes Philpott's division of the economy into a restructured and unrestructured sectors. The former covers mining, forestry, electricity, and communications, characterized as those which were largely government owned in 1984, and experienced substantial corporatization and privatization. It is evident that the sectors experienced a substantial increase in their productivity growth following these reforms, although this boost stopped after 1992/3.

Because the restructured sectors contributed only 10.3 percent to GDP in $1997 / 8$ rising to 15.7 percent in $1995 / 6$, their substantial productivity gains do not seem to have impacted greatly on overall economic performance. One way of judging this is that had the restructured productivity grown after $1987 / 8$ as it had before that date, (average) labour productivity for the whole economy would been only 2.8 percent higher in $1995 / 6 . .^{9}$ On this measure the corporatization and privatization program added a fraction less than .5 percent to productivity growth between $1987 / 8$ and $1993 / 4.10$

A further complication to this story is illustrated in Figure 6 , which shows a downward sloping relationship between productivity and employment as PP. The relationship is a variation of a production function in which (at any time) output is merely a function of employment. ${ }^{11}$ It shows that if employment is $\mathrm{OE}$, then the economy can produce on the production at $\mathrm{X}$, so the average productivity is given by $\mathrm{OA}$.

An increase in productivity can occur in two different ways. First the production function may move out, say to p'p', so for the same employment $O E$ the economy now produces at $\mathrm{X}^{\prime}$ and productivity increases from OA to OA'. This is called a "shift of the production function".

Alternatively if employment contracts from OE to OE', but the production function remains at PP, productivity also goes up from OA to OA'. This is called a "shift along the production function."

These two sort of shifts are staple items of first year

Figure 5. Average labour productivity in New Zealand for restructured and unrestructured sectors 1978 through 1996

Sgev/2 (0) per FTE

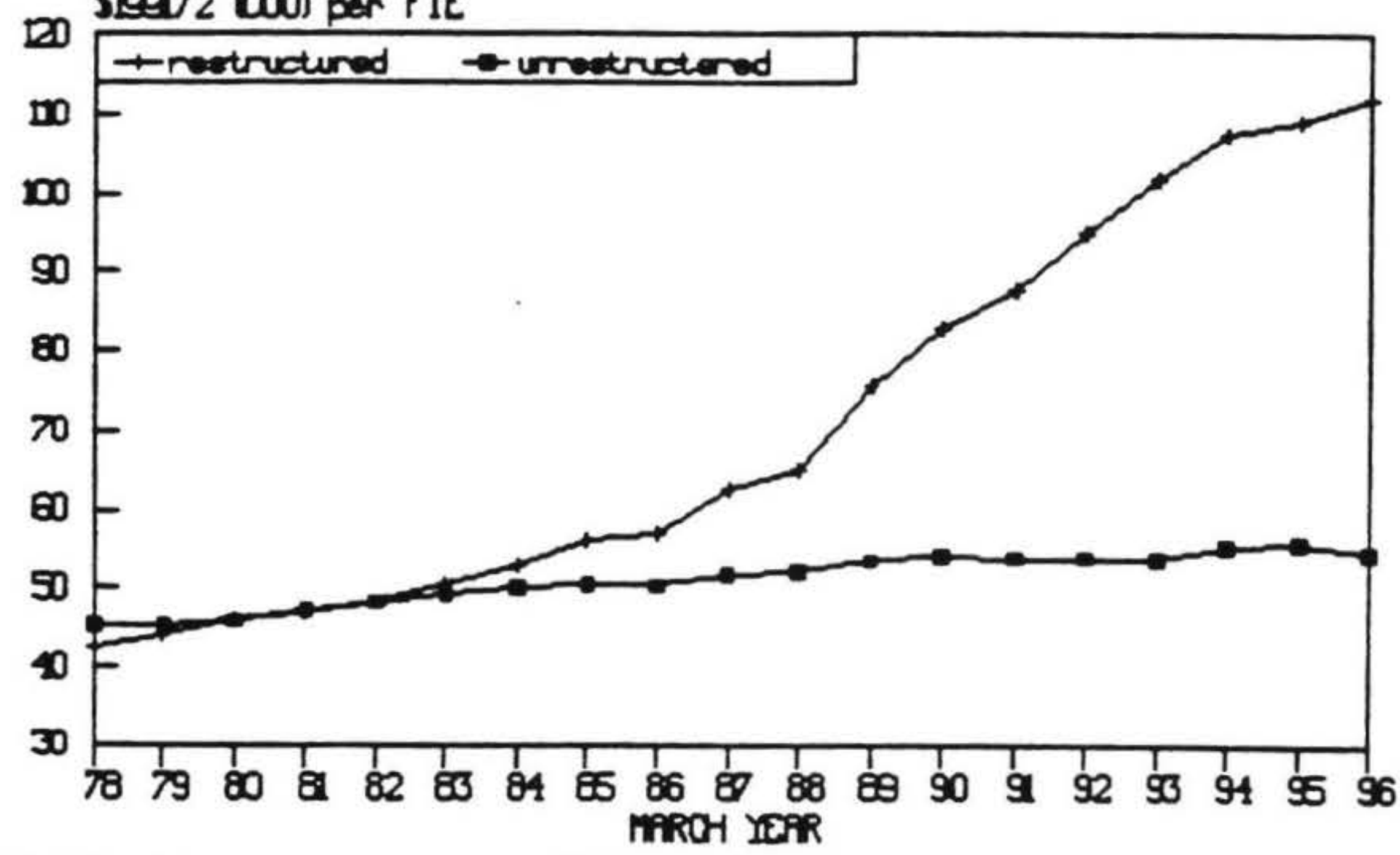




\section{Figure 6. The relationship between average labour productivity and employment}

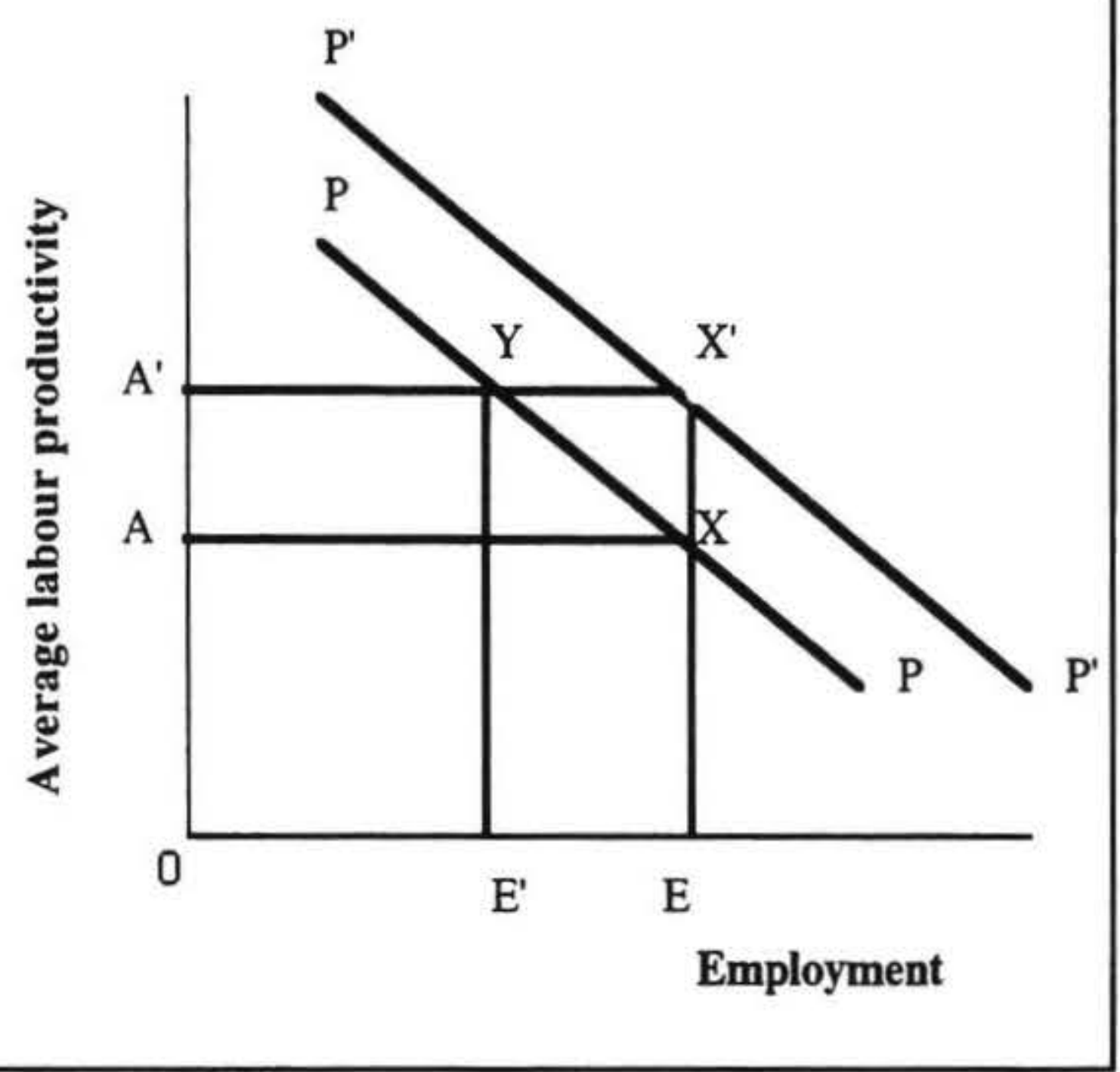

economics teaching. They are very different causes of a productivity gain, and they have different policy implications. It matters a lot whether the policy has resulted in higher overall productivity (that outward shift of the production function), or whether it has simply reduced employment (so unemployment rises by EE'), put a lot of firms out of business, and junked a lot of old capital without increasing (or even reducing) output or social welfare (the shift along the production function). ${ }^{12}$ Regrettably, claims that productivity has or has not increased are often made without reference to this important distinction.

In summary, Kasper's and others claims that the ECA increased productivity growth cannot be sustained on the basis of the available data. ${ }^{13}$ But can it be argued that the ECA decreased productivity growth, as Tim Hazeldine has done recently. ${ }^{14}$ That argument is more consistent with the available data, but the complexity of the situation is such, that more work needs to be done before we can be certain, for there are so many other things going on. It seems likely that the research will show that the ECA had very little impact on productivity in either direction.

\section{The economy and the ECA}

The story the data tells is that the post-ECA economy was in a stagnation phase until late 1992. It then began to expand rapidly, initially by using the internal resources of firms but later by an employing more labour. Productivity gains were not high. It would appear that this extensive rapid growth phase was over by the end of 1995, and the New Zealand economy has now settled down to a modest long term growth rate of just under 3 percent p.a, based primarily on increased application of labour and canital, with little underlying productivity growth.

Kasper is keen to explain this not very impressive expansion on the effects of the ECA. "It would be hard not to attribute most of this enhancement to the improved institutional framework surrounding labour markets" (p.45). Indeed Kasper could have been more explicit and said it was "easy" to explain the enhancement by the ECA. But easy explanations are rarely correct ones.

A richer account of the New Zealand growth experience of the mid 1990s is that there was a bounce back from the contraction/stagnation phase of the late 1980s and early 1990 s, fuelled by a favourable fall in the real exchange rate (which has since been reversed), a substantial improvement in the terms of trade (which are about 10 percent higher in the 1990s than they were in the late 1980s), and the upswing of the world economy (especially Australia, which in New Zealand's case is the main market for manufactures). However this expansion was based on additional applications of labour and capital, rather than improved productivity performance. When the available capital and appropriately skilled labour ran out, economic growth slowed down.

Which of these two accounts are to believed? Surely the poor productivity performance discriminates between them. If the Employment Contracts Act had worked in the way its proponents say it did, in the way which Kasper thinks it did, there should have been substantial an ongoing productivity gains. There have not been these gains, and so the ECA explanation of the expansion is not a viable one.

\section{Enthusiasm for the ECA}

Despite the lack of evidence of significant improvements in economic performance from the ECA there remains considerable enthusiasm for the legislation. Undoubtedly some of the enthusiasm among managers is because of the change in the industrial relations balance it engender over managerial employee relations. However in economic terms there has been one substantial economic gain for employers.

Figure 7 shows the real (income) wage (of Figure 3 ) divided by the labour productivity index (of Figure 2), which gives a measure of the degree to which productivity gains had ben shared with workers. ${ }^{15}$ The overall pattern is that the index fell about four percent in the mid 1990s, suggesting that workers' wages have not shared in the (albeit small) productivity gains over the period.

It would not be unreasonable to attribute this to the Employment Contracts Act. Such gains workers have had over the period have been the increasing number of jobs - which we have suggested are unlikely to be attributable in full to the ECA. There is therefore little evidence that the ECA has been beneficial to workers.

(Two further issues - unemployment, and the paper by Tim Maloney which Kasper extensively quotes, are dealt with in appendices.)

\section{Summary}

On the basis of the empirical evidence it is very difficult to 


\section{Figure 7. Wage costs to productivity in New Zealand, 1990 through 1996}

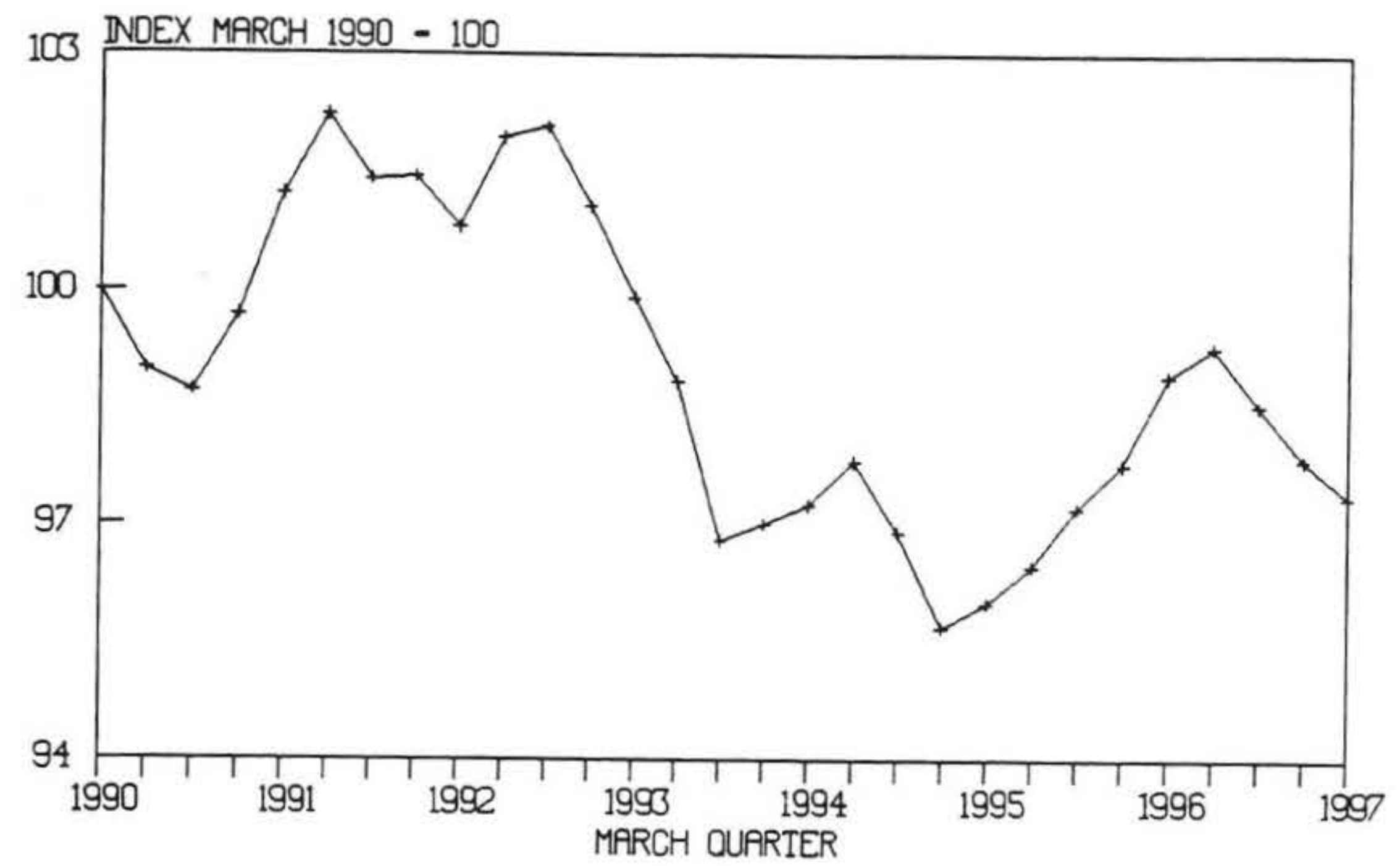

reach, in a systematic way, Kasper's conclusions about the beneficial effects of the Employment Contract Act. In particular the poor productivity growth rules out the likelihood that the ECA was a major contributor to the macroeconomic expansion of the mid 1990s. The Act would, however, seem to have contributed to the poor real wage growth, and the failure of many workers to obtain a share in any increase in prosperity of the 1990s.

\section{Future research}

One is puzzled. Undoubtedly those who have made up their mind about the economic impact of the Employment Contracts Act will find in the data evidence to support their prejudices, whether they believe the ECA beneficial or detrimental. (It is well to note that the opposition to the Act might argue too that there should be productivity gains, although in their case they would argue that the gains were at the expense of the working conditions.) Those of a more scientific bent can but continue to monitor the economic outcomes, perhaps at a more disaggregated level, in the hope there is some clue overlooked, some nuance yet to be observed. It may well be that the sort of macro-economic data used here, or the slightly more disaggregated data used by Tim Maloney and others, will not reveal much. Rather the need may be to look at worksites, and carefully evaluate to what extent the additional managerial freedom which the ECA allowed, resulted in new productivity inducing work methods, and to what extent it simply allowed managers to cut labour costs by cutting (or stopping increases in) wages and other elements of worker remuneration.

\section{APPENDIX I: Unemployment}

Undoubtedly there has been a substantial fall in the New Zealand unemployment rate since its peak in 1991 of 11 percent (or its shoulder of 1993). ${ }^{16}$ This is not surprising given the sharp rise in employment. However Figure 8 shows forecasters do not expect any further gains through to 1997 or thereafter. ${ }^{17}$ The slow GDP growth rate means that insufficient labour is being taken on to reduce unemployment, despite the poor productivity growth. Forecasters expect the unemployment rate will hover above 6 percent throughout the late 1990 s.

In assessing the unemployment rate it should be noted that the rate was probably below 4 percent in 1984 when the reforms began, 18 and as recently as 1988 the unemployment rate was below 6 percent. 19

Kasper compares the pattern of unemployment rates for Australia and New Zealand. Given his difficulty with dealing with New Zealand data, one is reluctant to rely too heavily on exact figures - comparisons of international data are always difficult. However undoubtedly New Zealand has had a greater fall in is unemployment rate than Australia, since its employment growth has been greater.

A note of caution needs to be added. Comparison of unemployment rates, assuming consistent definitions of employment rates, are dependent upon some assumption about labour force participation rates (LFPR). It is well established that LFPRs are subject to cyclical variation, tending to be more depressed when unemployment is high when those not employed are less active in seeking work while, conversely, when unemployment is low those previously in the not-in-the-labour force category seek work and may become unemployed. There are also secular changes - both the youngest and oldest age groups have had falling LFPRs, ${ }^{20}$ while the female LFPRs have been rising.

How then are we to compare LFPRs (and hence unemployment rates) between different countries (even if the statistical definitions are exactly the same)? This is a troubling question in the case of the Australia New Zealand compari- 
Figure 8. Unemployment in New Zealand 1990 through 1997

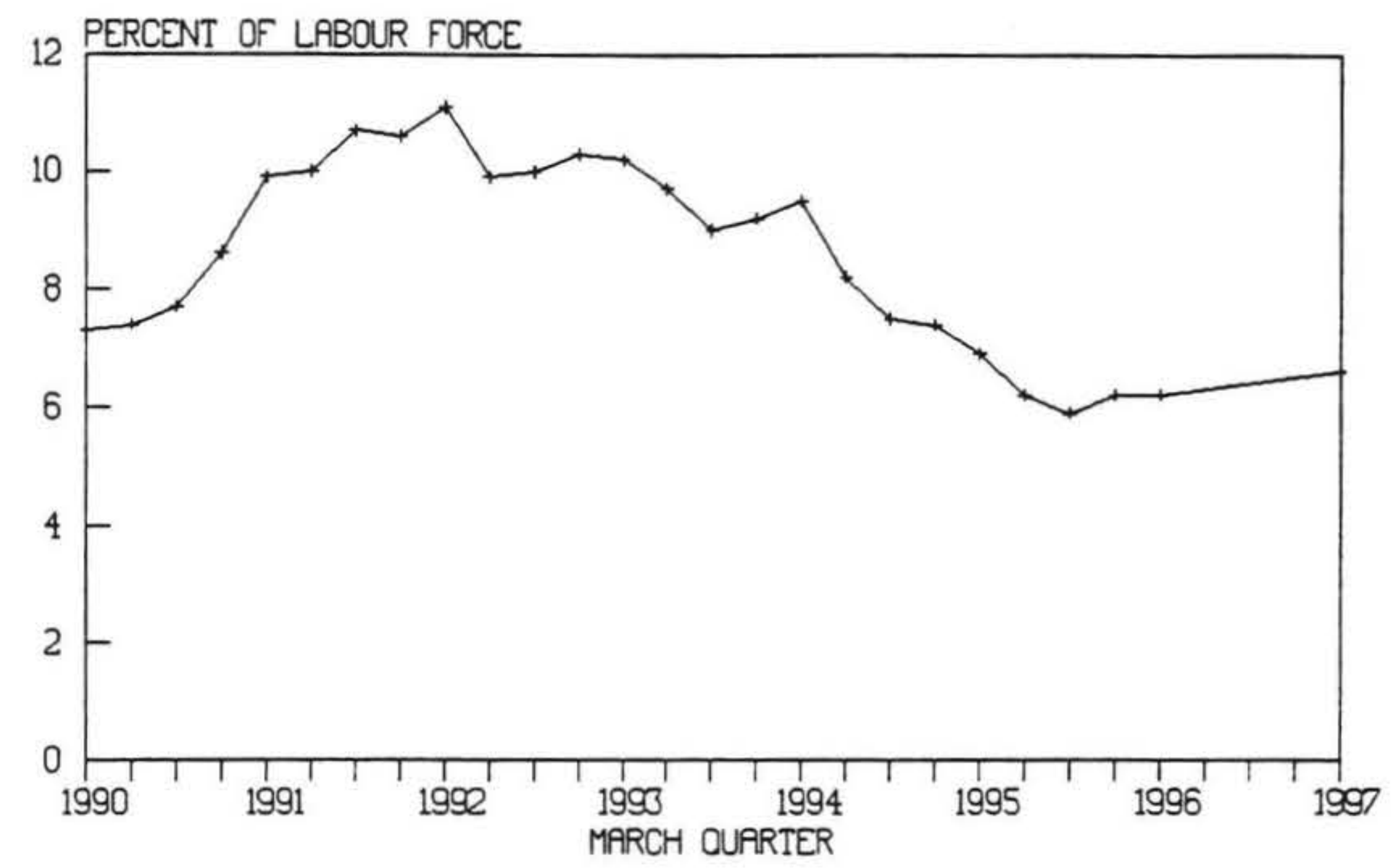

son. Historically the New Zealand LFPRs were higher than the Australian ones (but we do not know why). However males LFPRs have generally been falling faster here than across the Tasman (so that Australian male LFPRs are now similar to the New Zealand rates), while New Zealand females LFPRs have been stagnant while Australian ones have been rising (although Australian female LFPRs are still lower than New Zealand ones). This presumably reflects Australia's more vigorous secular employment growth, which has better retained men in, and attracted women into, the labour force compared to New Zealand. However we would want to know more about the LFPR levels before we told the story with confidence.

This is not to deny that measured unemployment is lower in New Zealand, and fell more between 1991 and 1995. The appendix simply notes that the comparison - indeed any international comparison - is complicated.

\section{APPENDIX II: The Maloney Study.}

This is not the place to provide a full review of Tim Maloney's "Estimating the Effects of the Employment Contracts Act on Employment and Wages in New Zealand." 21 However, Kasper quotes the paper favourably, so to ignore it might seem to practice that which the introduction condemned. All that is done here is warn that there are problems in using the work as significant evidence of the impact of the ECA on employment and wages.

The study by Maloney depends heavily upon a measure of union density, the proportion of workers who are union members. The union membership series comes from two sources: the Register of Unions up to first quarter 1989, and Raymond Harbridge's survey of trade unions in fourth quarter 1991 and 1992 (p.326-327). The two series are spliced together and the missing quarters are interpolated. Both actions raise difficulties.
Since the ECA is effected from second quarter of 1991, the series are on either side of the phenomenon which is being investigated. Any conceptual or measurement inconsistencies in the series may be econometrically magnified into a statistical difference which merely reflects the different data series. Even if Harbridge was as successful as he hoped in maintaining continuity, two further difficulties would remain. First, the series were measured at different times in the seasonal cycle. Second, many unions reported spuriously higher membership numbers under the old regime, but the new regime forced them to be more accurate (as when union amalgamation resulted in the acquiring union discovering here were far fewer members than were claimed).

The interpolation generates a spurious accuracy in the data. Altogether Maloney has 8 data points ( 6 before the ECA was introduced and 2 after), which he increases to 30 by interpolation. Now the econometrics is unaware of this, and so treats the data as though there are 30 independent observations of union density from a single data set, whereas there are only 8 independent observations from two separate data sets. The econometric impact of this is complicated, but as a first approximation we would expect the addition of interpolated data could halve the standard errors of the estimates of the coefficients on the union density variable. ${ }^{22}$ There is only one set of equations where the union density variable is identified as significant (Table 3) (albeit at only a ten percent level on a two tailed test). Allowing for the interpolated data would make these results even less statistically significant.

What this means is that in none of the estimated equations does Maloney find convincing statistical evidence of the impact of either the Employment Contracts Act directly, or indirectly via its impact on union density, on employment or wages. Maloney as much as acknowledges this when he writes "[s]uppose we accept that the ECA ... has resulted in increases in employment?". 
But suppose that the econometrics had found a statistically significant relationship between the ECA and employment (and/or wages), after full allowance for the splicing and interpolation. Correlation is not the same thing as causation. There were many other policy (i.e. broadly exogenous) changes happening at about the same time. ${ }^{23}$ To be compelling, the study needs not only to find a statistically significant relationship, but to demonstrate that there is no more plausible alternative explanation.

As it happens the study did not find the former, and we are left with the impression that the main factors determining employment and wage rates over the first two post ECA years were macroeconomic variables like output and relative prices.

\section{Notes}

\section{W. Kasper (1996)}

\section{NZIER (1996) Consensus Forecasts, April 1996, NZIER, Wellington.}

3. Kasper says the recession came to an end in early 1991 , but that gives more confidence to the quality of the GDP data than many would trust. The general impression, supported by the NZIER Quarterly Survey of Business Opinion, is that 1991 was a depressed year.

4 Since September, many forecasters have been revising down their forecasts for the $1996 / 7$ and $1997 / 8$ years, so the December consensus forecasts are likely to be even more pessimistic.

5. Kasper does not define his variables even there are a number of possibilities. The numerator of Figure 2 is Average Hourly Earnings (ordinary time), the denominator is the Consumer Price Index.

6. If Kasper is to be believed, the productivity gains are even less. "Some knowledgeable observers believe that employment statistics under-report employment growth since the ECA." (p.49) Who these "knowledgeable" people are is not explained.

7. B.P. Philpott (1996) The employment series is adjusted for part-time working.

8. The non-tradeable sector has higher labour productivity levels than the tradeable sectors, is because it includes the capital intensive energy, communications, and home ownership sectors.

9. The calculation assumes that the sectors' output would have grown at the same rate without the additional productivity growth.

10. Conversely, and making a series of assumptions to get an order of magnitude, there would have been an extra 39,000 workers employed in the restructured sectors, and unemployment would have been 77,000 or 4.1 percent in March 1996. This was the level similar to that which it was in the mid 1980s (there was no HLFS at this time).

11. If $\mathrm{Y}=\mathrm{f}(\mathrm{E})$, which is a production function, then $\mathrm{Y} / \mathrm{E}=\mathrm{f}(\mathrm{E}) / \mathrm{E}$, which is the form of the function shown in Figure 6.

12. Output when the production function shifts is OEX'B which is definitely larger than previous output OEXA. Whether output under the shift along the production curve increases (i.e. whether OE'YA'>OEYA) depends upon the slope of the production function.

13. The NZIER reports that a survey of managers reported "increased productivity and operational flexibility and greater training." Given there is no statistical evidence for substantial gains in productivity above the long term trend, one might conclude that mangers are attributing normal productivity gains to the ECA, in a similar manner to Kasper attributing favourable economic events since 1991 to the ECA, despite there being little economic evidence to support his contention. QSBO March 1996.

\section{T.Hazeldine (1996).}

15. There is an issue as to whether the real income wage or the real product wages should be in the numerator. Real income wages were used here because they were illustrated in Figure 2. Thus the measure indicates that workers have not benefited from the productivity gains in their takehome pay.

16. Kasper's data seems to be seasonally adjusted. They have since been revised. Presumably the "white" male unemployment rate refers to the European/Pakeha rate."White" is not used in this context in New Zealand because of its racial connotations. The official categories involve ethnicity rather than race.

17. Unlike Kasper's graph, the vertical axis of Figure 5 is not truncated, avoiding the impression of greater relative gains than actually happened.

18. This particular series does not begin until 1986.

19. But note endnote 10 of the main paper.

20. The falling youth LFPR reflects more young people staying on in tertiary institutions (but also perhaps the greater difficulty of their finding work, since a full-time university who was doing a little work appears in the labour force statistics as part-time employed). The falling LFPRs for older age groups are thought to reflect changes in retirement choices, but again may also be influenced by job scarcity inducing early retirement.

21. Maloney, T. (1994).

22. $(8 / 30)^{1 / 2}$ is approximately 0.5 .

23. For instance while one is not surprised by the conclusion 
that the ECA reduced union density (indeed one would be astonished otherwise), the successful econometric equations demonstrating this are hardly compelling evidence.

\section{References}

Hazeldine, T. "Employment Contract Act makes for bad economics," New Zealand Herald, November 25 .

Kasper, W. 1996 Free to Work: The Liberalization of New Zealand's Labour Market, Policy Monograph 32, Centre for Independent Study, Sydney.

Maloney, T. 1994 "Estimating the Effects of the Employment Contracts Act on Employment and Wages in New Zealand," Australian Bulletin of Labour, Vol 20, No 4, December 1994, p.320-343.

Philpott, B.P. 1996 A Note on Recent Trends in Labour Productivity Growth, Research Project on Planning Paper 281, Wellington, October 1996.

\section{Author}

Brian Easton is a Research Economist and Social Statistician for the Economic and Social Trust on New Zealand, 18 Talavera Tce, Kelburn, Wellington. 